\title{
A Web-based E-Library System for Tertiary Institutions
}

\author{
Moshood Alabi Alarape \\ Department of Computer Science \\ Federal Polytechnic, Bida. Nigeria
}

\author{
Samuel Ndifreke Edet \\ Department of Computer Science \\ Federal Polytechnic, Bida. Nigeria
}

\begin{abstract}
An e-library system is a very important element of the internet age libraries. A library without it may face a lot of challenges like the lack of adequate visitation by the users. This paper presents an e-library system that was developed using PHP programming language, HTML and CSS for design and MySQL as a backend database technology to run on Apache v3.21 application server and Mozilla FireFox web browser. The system allows multimedia sources to be accessed by the users of the library and was able to eliminate the problems of unavailiability of library resources, inadequate space, physical bounding and restricted access that characterized the traditional library system.
\end{abstract}

\section{General Terms}

Information Systems

\section{Keywords}

e-library system, PHP, HTML, Multimedia, MySQL

\section{INTRODUCTION}

A library is a collection of sources, resources, services and the structure in which it is housed [1]. Libraries have always been a community's portal to information, knowledge and leisure. It is a community's gateway to information from many sources either nationally or internationally beyond the shelves of the users [2].

The existence of a library in any academic institution is an invaluable asset that is as important as the institution itself. Libraries offer the users the opportunity to have access to academic materials like journals, magazine, books, videos and others that boost the knowledge scope of the users in their different areas of research or discipline. In fact [3] said it all when they affirmed that effective teaching and learning cannot take place without adequate provision of library resources.

The volume of materials being dealt with in the libraries are so much that an individual may not have the financial capacity to acquire them - this is very true with the level of the students of the institutions and the high cost of electronic sources online. The advancement in Information Technology, most especially the existence of internet has brought about the globalization of resources and makes sharing of resources possible irrespective of the geographical locations. This has removed the access restriction to various resources online to a great extent. Even though it is not all existing useful library materials that may be available on the internet it still provides a seemingly large access to vast volume of resources for academic use.

This suggests that a blended approach of combining the traditional system of library with that of the electronic library will expand the volume of academic resources that will be made available to library users. The e-library system developed and presented in this paper supports such an approach.

\section{OBJECTIVES OF E-LIBRARY SYSTEM IN A SCHOOL SYSTEM}

The main goal of digitalization in academic library is to promote library use through effective services. Local and international recognition and respect are partly determined by quick accessibility to published works. Some highly productive scholars globally have been found to be more information rich than their counterparts. This implies that information adds significantly to the existing knowledge of the users. The information resources and services available in institutional information systems (library, archives, records offices, and documentation centers) are digitalized and create databases capable of supporting research activities. The shift from print to electronic information means that both academic staff and students in a school system must use these resources for better quality, efficient, and effective research more than ever.

Other objectives of e-libraries in school system according to [4] are:

- To speed up the systematic development of the means to collect, store, and organize information and knowledge in digital form, and of digital library collections.

- To promote the economical and efficient delivery of information to all parts of society

- To strengthen communications and collaboration between and among the research, business, government and educational communities.

- To contribute to the lifelong learning opportunities of all people.

The cardinal objectives of academic libraries are designed primarily to serve their parent institutions most especially by meeting the teaching, research, and learning needs through provision of the services (conventional and digital) that can lead to an increase in the productivity of their students, teachers and researchers [5].

\section{REVIEW OF RELATED WORKS}

The system design of an online Library Management System project was presented by [6]. The system is to manage the online borrowing and returning of books from a library to registered members of a reading group. The system allows the members to share books online and it contains facilities for adding new books, issuing of books and returning of same books. The system does no other than these. 
A framework of a web-based digital library management system for institutions and colleges was presented in [7]. The framework was very similar to the one presented in this study only that they focused on digital library instead of e-library concept as has been the pre-occupation of this present study.

[8] presented a web-based system that provides a simple interface for quick book searching, lending and mainly used for the common browsers, making the system migration and usage easier. The only different between this work and our study here is the non-inclusion of the multimedia sources viewing and usage as done in our study.

The work of [9] was also exactly similar to that of [8] only that they provided command options alternative in Arabic language that allow the Arab users to interact with the system. The work was implemented on Java platform using Java Applets. This study has the same difference with ours as the work of [8].

[1] designed a web-based integrated library system which was able to automate most of the existing library functionalities. An internet security solution was incorporated, specifically web-based Kaspersky 2000, which was installed on the server hosting the system to protect the system from all network threats when the system functionalities are put into use.

\section{MATERIALS AND METHODS}

Sample electronic books online on different courses being offered in the polytechnic used as case study were gathered, academic videos and audio tutorials on different areas or discipline were also collected.

The e-library system was developed using HTML (Hypertext Markup Language) and CSS (Cascading Style Sheets) for the design, PHP - a Hypertext Preprocessor programming language for coding with MySQL as a back-end database technology that runs on Apache v3.21 application server and Mozilla FireFox web browser.

The block diagram in Fig. 1 shows the architecture of the proposed system.

\section{RESULTS OBTAINED}

The newly developed software for e-library system was tested using some input like e-books, audio and video tutorials gathered and the output obtained were all according to the intended specifications.

Some of the user-interfaces from the running of the system are shown in Fig. 2 through Fig. 10.

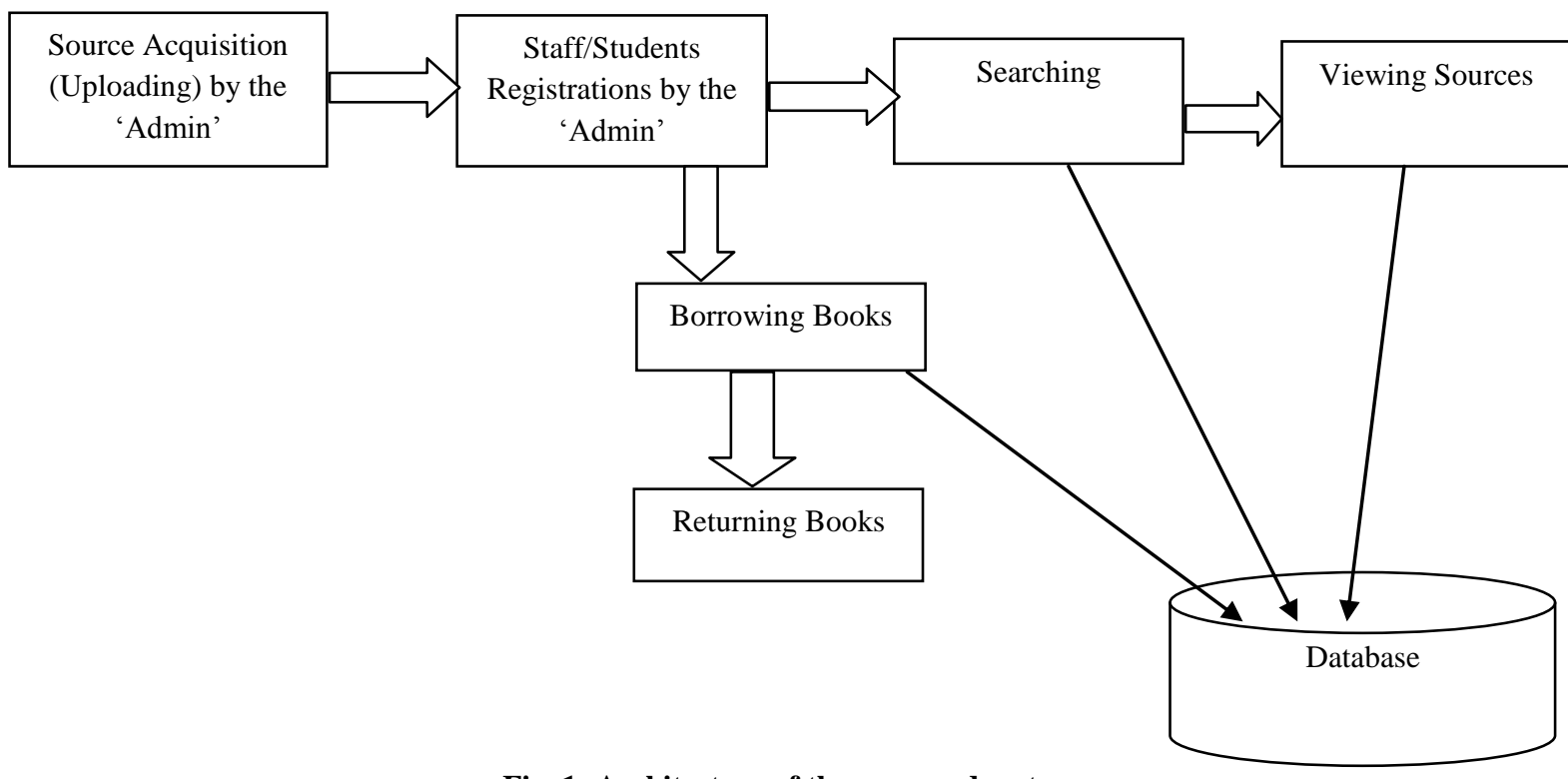

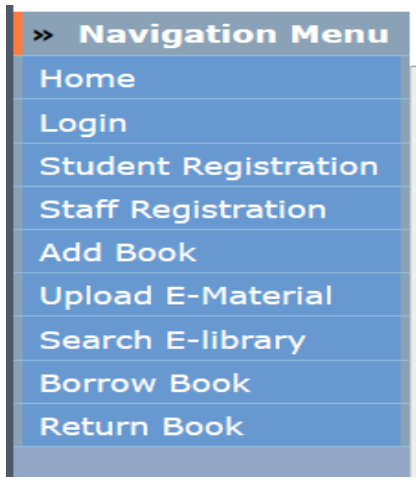

Fig. 1: Architecture of the proposed system

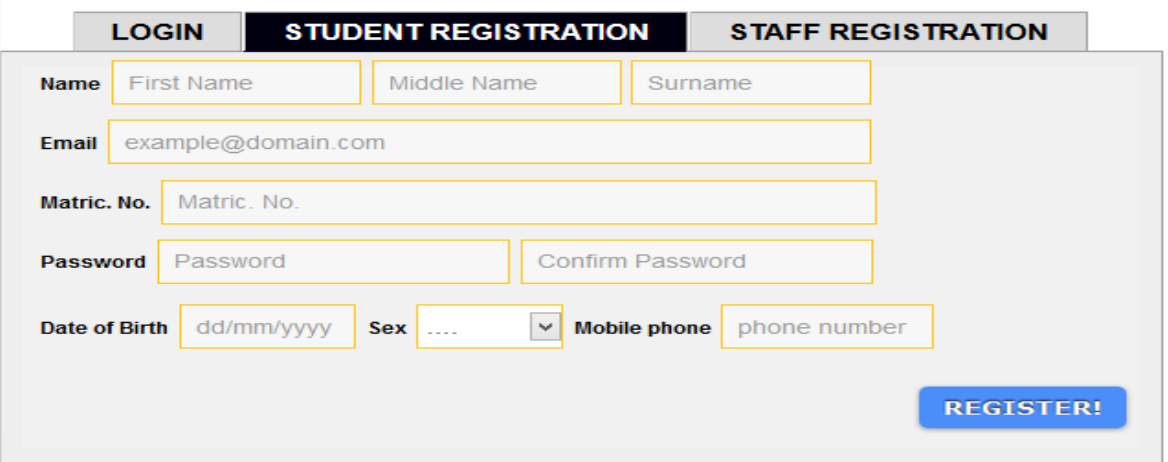

Fig.2: Staff/Student Registration page 


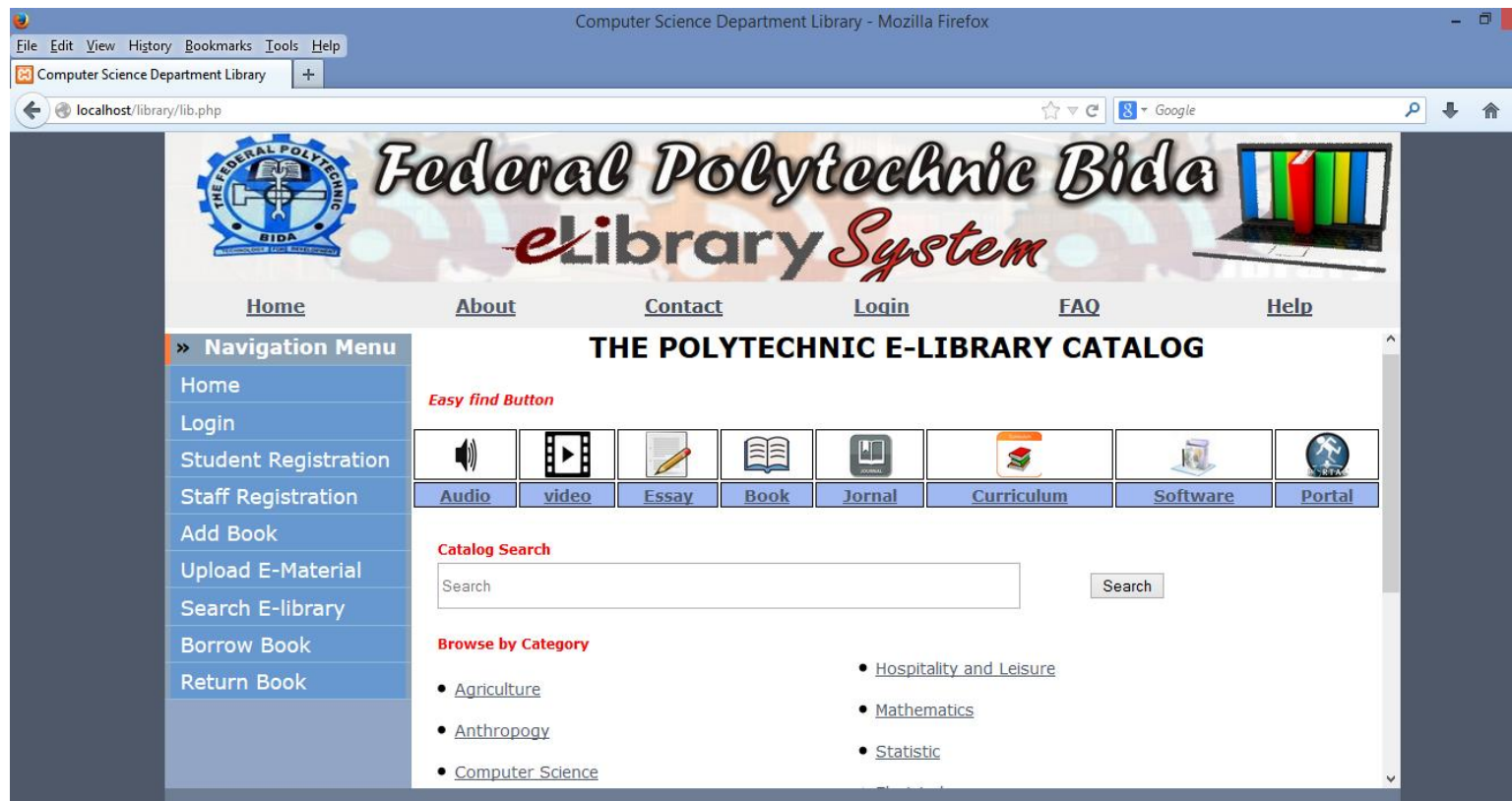

Fig. 3 E-library system Management Page

\section{» Navigation Menu Home \\ Logout \\ Student Registration Staff Registration \\ Add Book \\ Upload E-Material \\ Search E-library \\ Borrow Book \\ Return Book}

\section{\begin{tabular}{l|l}
\hline ADD BOOK UPLOAD E-MATRIALS \\
\hline
\end{tabular}}

Title

Author Book Author

Publisher Book Publisher

Quantity Quantity

Department

Fig. 4: Add-Book Page
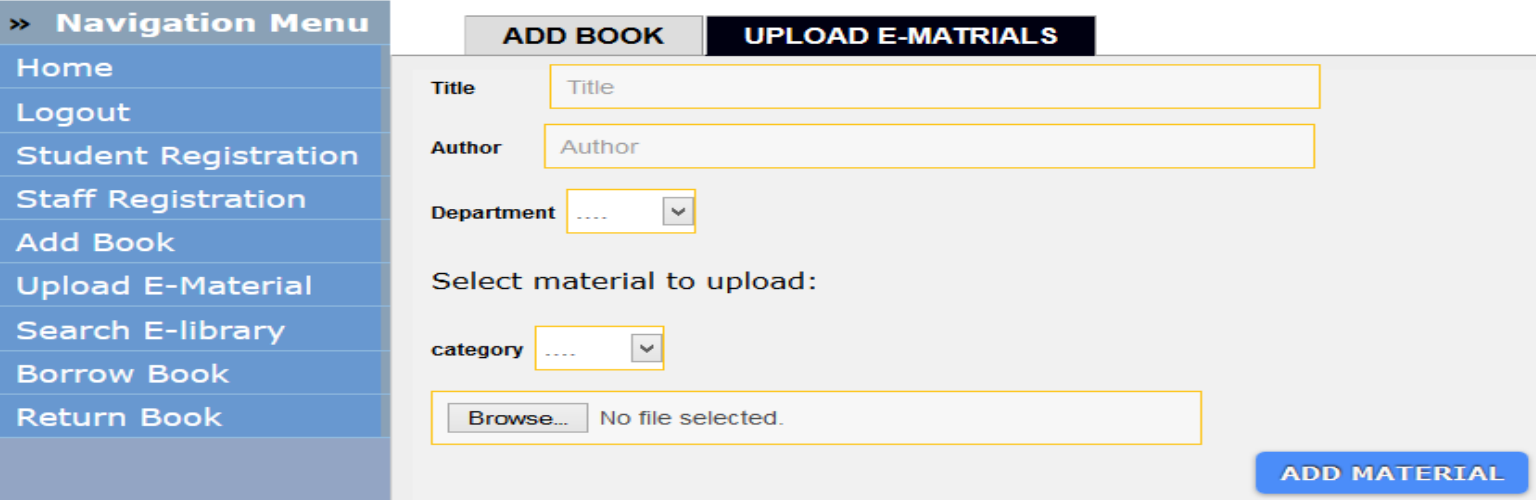

Fig. 5 E-Material Upload Page 


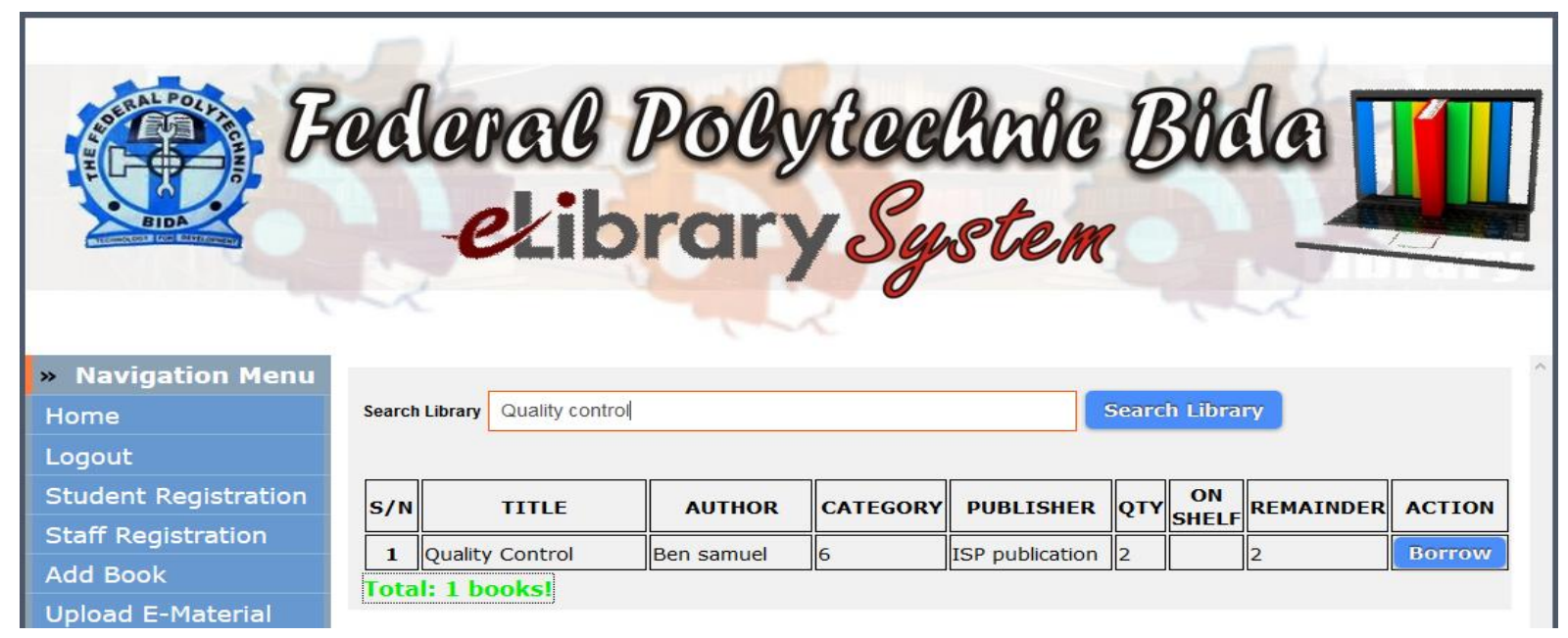

Fig. 6 Book Search

》 Navigation Menu

\section{Borrow Book}

Home

Logout

Student Registration

Staff Registration

Add Book

Upload E-Material

Search E-library

Title Quality Control

Borrow Date October 3rd, 2016

Return Date October 10th, 2016

User

Fig. 7 Borrowed Desk

"Navigation Menu

Home

Logout

Student Registration

Staff Registration

Add Book

Upload E-Material

Search E-library

Borrow Book

Return Book

Teach Your Self Java Programming In 21 Days

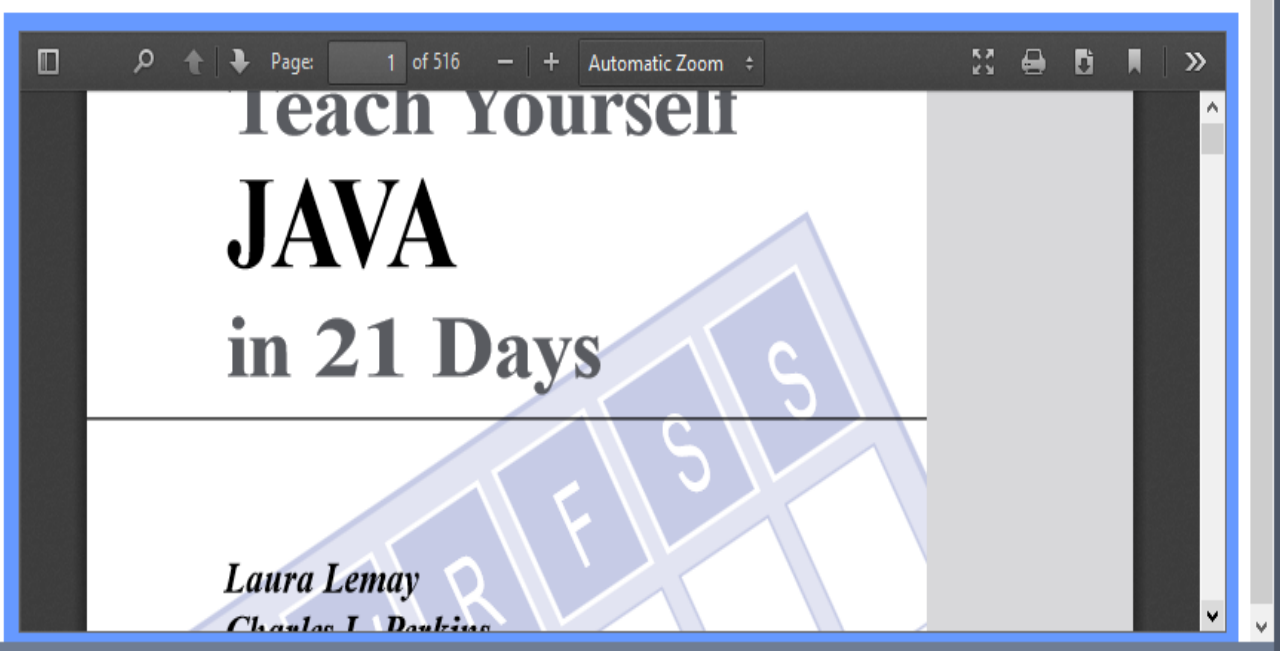

Fig. 8: Viewing E-book 


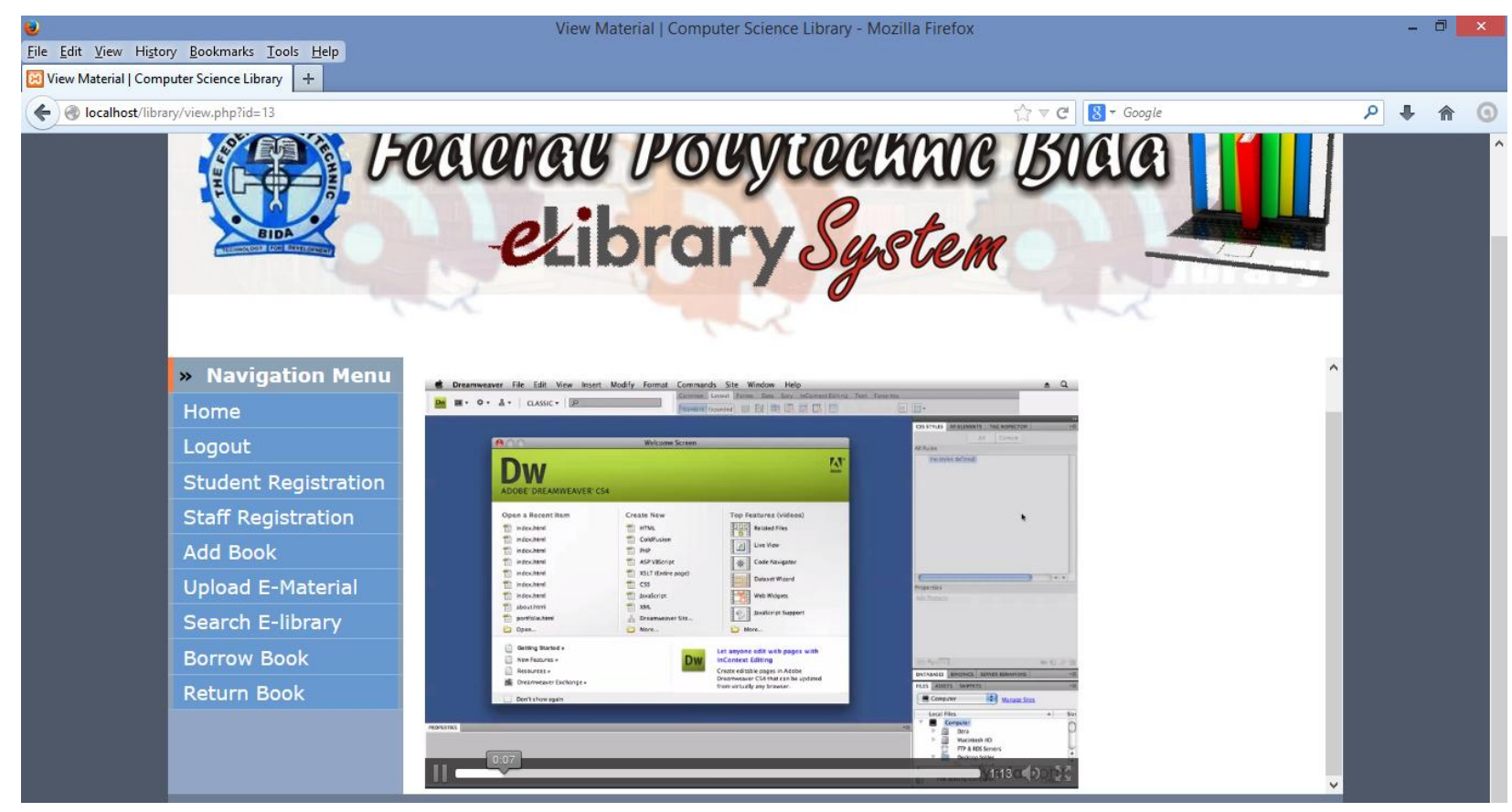

Fig. 9 View Video

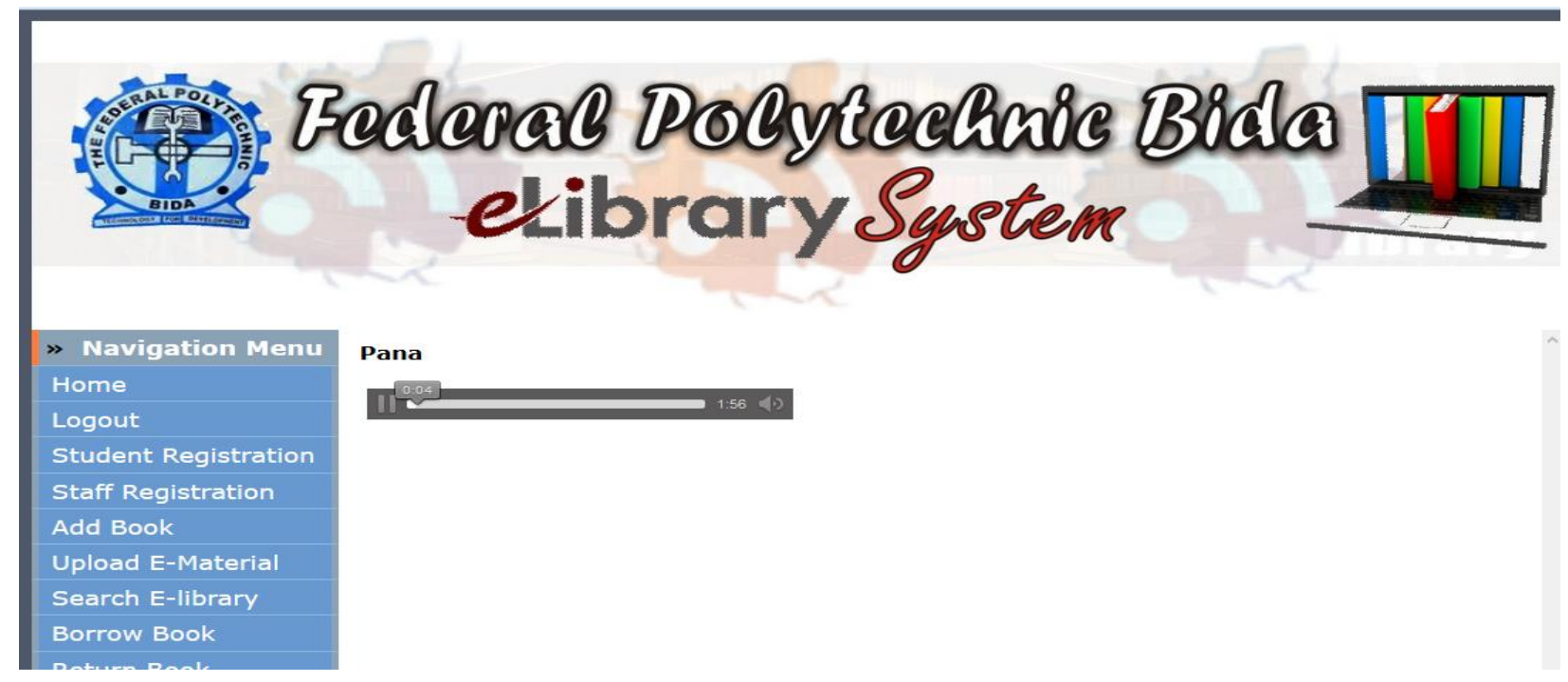

Fig. 10: Playing Audio

\section{DISCUSSION}

The e-library system developed in this work, from which some of the interfaces are being shown, offers a lot of functionalities.

The system is designed to support three level of user; Admin, students and staff. The students and staff have to register and logged in as users before they can access the library system.

The functionalities of the admin in the system is to register new users, add hard copy materials to the library based on categories, upload e-materials (e-books, audios tutorial, video tutorial, images, journals etc.) to the library based on categories, and send the outdated materials to the archive section of the library.
In summary, the e-library is a user-friendly system which provides platforms for the user to carry out the following activities:

i. Borrow hardcopy materials from the library and return it when due with the help of the 'Admin'.

ii. Search for an e-material using different categories.

iii. View e-books in a Portable Document Format (PDF) through e-book viewer.

iv. Listen to audio tutorials through audio player.

v. Watch video tutorials of .mp4 or .ogg format using video player.

vi. Get a link to the original website of the resources being searched for. 


\section{CONCLUSION}

The consideration for the adoption of e-library system might appear costly at first because of the infrastructure that needs to be put in place, but what is apparent is that its adoption in tertiary institutions is paramount.

The e-library system is a tremendous improvement on the traditional library system that is prevalent in schools today because it improves educational activities and minimizes the workload and time spent in storing, accessing and retrieving materials from the traditional library. The use of this e-library system will successfully bring about ease and efficiency to existing system, which is characterized by manual, time consuming and rigorous processes.

The e-library system, an electronic and a web-based system has been able to address the problems of the traditional library system by offering features like round the clock availability, removal of physical bounding, multiple accesses, easy information retrieval, provision of unlimited storage space, networking of operations and low cost of maintenance.

The extension of this work is going to be in the embedding of the other library activities that are not captured by the system for a holistic library software solution.

\section{RECOMMENDATION}

This e-library system is recommended for all tertiary institutions for library services efficiency and effective. The experimental case study used in this work does, in no way, affect the adoption of the system by similar institutions with standard academic libraries.

\section{ACKNOWLEDGMENTS}

We thank the management of the Polytechnic Library and her staff for providing the necessary information during data collection for the development of the proposed system.

\section{REFERENCES}

[1] Sanni, A. S., Adedoyin, A. and Oloyede, M. O. (2013). The Design of a Web-Based Integrated Library System with Internet Security Solution. The Journal of Computer Science and Its Applications. Vol. 20, No 2, Pp. 77 - 92.

[2] Rathje, B. D., McGrory, M., Pollitt, C. and Voutilainen, P. (2005). Designing and Building Integrated Digital Library Systems - Guidelines. International Federation of Library Associations and Institutions (IFLA) Professional Reports, No 90. Available at https://www.ifla.org/files/assets/hq/publications/professi onal-report/90.pdf. Accessed on 16th June, 2016.
[3] Obaseki, T. I., Maidabino, A. A. and Makama, F. H. (2012). The Development and Challenges of Virtual Library Services in Nigerian Colleges of Education. Trends in Information Management (TRIM) Vol. 8, No 1 , Pp. $1-8$.

[4] Li, X and sFurht, B. (2014). Design and Implementation of Digital Libraries. Available at www.cse.fau.edu: www.cse.fau.edu/borlo/chpter18ic.pdf.nd Accessed on 30th June, 2016.

[5] Trivedi, M. (2010). Digital Libraries: Functionality, Usability and Accessibilty. Library Philosophy and Practice. 2010. Available at http://www.webpages.uidaho.edu/-mbolintrivedidiglib.htm. Accessed on 16th June, 2016.

[6] Bhupendra, S. B., Panwar, S. and Vaishnav, V. Online Library Management System. Project Report submitted as a Partial Fulfillment of the Requirement for the System Design Project of Masters of Computer Application at Rajasthan Technical University, Kota. Available at www.iisjaipur.org/.../11.Projectonline \%20library\%20management\%20system.pdf. Accessed on 20th March, 2017.

[7] Tochukwu, C., Nwachukwu-nwokeafor, K. C. and Udeani, H. (2015). Designing A Web- Based Digital Library Management System for Institutions and Colleges. International Journal of Innovative Science, Engineering and Technology. Vol 2, Issue 3, Pp. $464-478$.

[8] Jiawei, J. (2011). Web-Based Library Management System with PHP and MySQL. A Bachelor's Thesis submitted to the Department of Information Technology (Specialization in Network Communication Technology). Turku University of Applied Sciences. Finland. Available https://www.theseus.fi/handle/10024/28910. Accessed on 20th March, 2017.

[9] Kamel, M. J. and Hassan, N. H. (2012). Design and Implementation of a Web-Based Library. A Project Report submitted to the College of Science, University of Baghdad in Partial Fulfillment of the Award of BSc. Degree in Computer Science. Available at https://www.scbaghdad.edu.iq/projects/computer/201020 11/11.pdf. Accessed on 30th March, 2017. 